\title{
PROFESSIONAL ETHICS IN ACCOUNTING: CASE STUDIES IN LIFEWIDE LIFELONG LEARNING PROGRAMMES
}

\author{
Anna Karmańska \\ Warsaw School of Economics, Poland
}

\begin{abstract}
The article focuses on professional ethics in accounting in the Lifewide Lifelong Learning (LLL) educational programmes. It is aimed at the presentation of the experience in introducing case studies on ethical dilemmas to professional accounting training. It presents the own experience of the author, who is closely connected with teaching university students as well as with the LLL professional education.

Presenting ethical dilemmas as a form of teaching, the author claims that they are effective in developing sensitivity to professional ethics and in reinforcing the principles included in the codes of professional ethics in accounting. She is convinced that they may be successfully applied in the LLL programmes, but only when the trainers are well prepared for it. The article does not present any literature cases, but includes a proposal which may be important for the teaching of accounting within the LLL programmes as well as at universities.
\end{abstract}

Keywords: accounting, Lifewide Lifelong Learning (LLL), ethics, case study

\section{JEL Code: M41}

\section{Introduction}

The conditions in which accounting information systems operate in practice require a strong concentration on the problem of ethics in business and ethics in reporting information about its performance. The awareness of this relation is not a novelty. An honest man dealing with business and accounting has had to do with it for ages. However, an educational need in this area appeared relatively recently. "Calls for teaching more ethics in accounting education have come in from the American Assembly of Collegiate Schools of Business (AACSB, 1988), the American Accounting Association (AAA, 1986), the American Institute of CPAs (AICPA, 1988), the Accounting Education Change Commission (AECC, 1990), the National Commission on Fraudulent Financial Reporting (NCFFR, 1987), and from the "white paper"' jointly written by the largest accounting firms (Arthur Andersen \& Co. et al., 1989)" (Armstrong, Ketz, Owsen, 2003, p. 2).

The problem of ethics education in accounting is complex for three reasons at least. At first, the literature focuses on a number of contexts in which the problem of ethics in accounting appears and on a great variety of human activity in which ethics in accounting is significant. A good review is provided by a 4-volume collective publication from 2013 (McPhail, 2013). On nearly 1,500 pages the authors created a detailed problem map of this kind of professional ethics.

Secondly, it is very important in teaching professional ethics in accounting to identify the level of ethical sensitivity of students/participants who we will have to do with during our classes. It may be interesting here to consider the findings of research conducted in order to survey students' opinions about ethics related to professions pursued within accounting (Koumbiadis, Okpara, 2008) as well as the indication of possibilities of using cultural differences in the ethics educational process within accounting curricula (Mirskehary and Yaftian, 2009). 
Thirdly, the teaching of ethics in accounting is a challenge as it is not enough here to know only the rules resulting from the codes of professional ethics (e.g. Code, 2007, Code, 2016). It is necessary to permanently improve teaching competences in this area, which is closely connected with the need for monitoring different research indicating new trends and phenomena, important to maintain the drive towards "professional ethics in accounting". Gaining an insight into the problems in this area is not an easy task. It is important then to pursue a methodological search for it. The categorization of the available literature on teaching ethics in accounting may facilitate it. As a framework here could be utilised Thorne's 1998 Integrated Model of Ethical Decision Making. (Armstrong, Ketz, Owsen, 2003).

Many other features, aspects and determinants which are important for the accounting ethics education may be indicated. There is no doubt, however, that at present it is absolutely indispensable to include the issue of professional ethics in the accounting curricula, in all countries, irrespective of cultural determinants and religious traditions (Maruszewska, 2011; Said, Al-Tarawneh, 2013].

The professional accounting education including blocks devoted to professional ethics meets the recommendations included in the International Education Standards (IESs), which have been issued by the International Federation of Accountants (IFAC) in order to improve the programmes and methods of training of accountants and professional accountancy candidates. The IFAC educational standards determine the desired effects of education and support the Lifewide Lifelong Learning (LLL) programmes in accounting. The significance of the issue of professional ethics in this kind of education is indicated by the fact that within the set of eight educational standards one International Education Standard (IES 4 Initial Professional Development-Professional Values, Ethics, and Attitudes) was devoted entirely to the values, ethics and professional attitudes [www1]. This standard may be useful for everybody that offers respective accounting professional programmes or affects the shape of their contents. Its stakeholders may include a professional organisation of accountants, a university, a regulator responsible for accountancy supervision, a government institution responsible for legal and regulatory requirements connected with the accounting professional education.

The present article does not analyse the IES 4 content, which is found on the IFAC website. The author wishes to introduce some experience of the Ethics Commission of the Board of Accountants Association in Poland, which has been chaired by her since 2006, and which refers to the implementation of principles of professional ethics in accounting in the LLL programmes, conducted by the Association, which is one of the largest LLL educators in the area of accounting.

The way to be covered in order to implement the principles of professional accounting ethics in educational programmes is altogether different and decisively more difficult from the one which may be imagined on the basis of implementation of a substantive programme including solutions resulting from the balance law. There are a few reasons behind this difficulty.

First, ethics is a "soft" teaching area, and the specific character of teaching of professional ethics may in a way discourage or go beyond the capabilities of people dealing with accounting teaching, which is most often very concrete and hard due to the character of the issues.

Second, teaching the content with regard to professional ethics, including the presentation of the code of ethics, is frequently, if not generally, made difficult by the conviction among participants/students that ethics cannot be learned, because your conduct may be either ethical or not. This conviction needs to change. And on a large scale, for example the national scale, 
it never becomes effective quickly. The principles showing a specific character of professional ethics in this area and its significance for doing business honestly should be instilled long in advance, even if it is a matter of years, and exposed in the whole professional accounting environment and outside it. The way of acting in this domain depends to a large extent of cultural determinants. It also depends on the involvement of people and institutions whose activities in relation to the need for the exposition of professional ethics result from a true (and not merely fashionable) care about professionalism in accounting and from the awareness that at present as well as in the future professionalism and professional ethics will determine the social status of accountants.

Third, educational effects in the area of professional ethics, unlike the knowledge of the subject matter, are difficult to verify. In the case of the latter, the degree of competence is verified by a variety of tests and problems to solve. In the case ethics it is difficult to find out to what degree the principles of professional ethics are truly and thoroughly anchored in the hearts and minds of the course participants. It is not important only to find out whether or not the participants know the wording of principles of the code of professional ethics. It is more important for them to understand and be able to apply them in practice.

Fourth, in order to make the education in the area of professional ethics bring expected results, teaching of the principles of professional ethics should be completely different from that of the substantive knowledge of accounting. It should be conducted in such a way as to provoke deep reflection and wavering and lead to the examination of conscience. This kind of teaching is not easy. The lecturers should not only be well prepared and choose a proper teaching moment but they should also apply good teaching methods. They should know psychology and should be able to meet the coaching tasks in the area of ethics. It may be quite a challenge for accounting lecturers.

\section{Lifewide Lifelong Learning (LLL) in accounting}

There is no doubt that accounting is an area really susceptible to changes on various planes of business activities pursued by man on both micro- and macroeconomic scales. Frequent changes in the balance law creating a framework for a reliable description of performance produced within this activity are quite a challenge for people professionally connected with accountancy. The canon of the accounting language changes very often and substantially too, and this means that there is a permanent need for learning and for the acquisition of increasingly demanding professional competences.

Much may be written about why it is so and what the global accounting policy is. However, it is enough to state here that the global accounting policy and domestic regulations resulting from it make a traditional term accountancy become a notion referring to a wide spectrum of knowledge, skills and attitudes which jointly determine a good professional preparation.

Under such conditions LLL in accounting is a challenge for many educators (see more on the framework of the LLL implementation in accounting within the Polish practice: Karmańska, Grabowski, 2014). They have to cope with the problems the solution to which guarantees an educational success in the LLL specific forms. These problems include:

1. necessity for the development of a validation system, i.e. a system of identification, assessment and confirmation of learning effects in the area of accounting;

2. necessity for the development of a qualifications system in cooperation with employers, staff and entities involved in accounting education;

3. preparation of programmes taking into account the real needs of employers and employees (Grabowski, Karmańska, 2014). 
In Poland the response to these challenges comes from the Accountants Association of Poland working on the system of certification within which there are four levels of qualifications [www2]. The system seems to be coherent in all respects. It corresponds to the assumptions of the lifewide learning (guarantees an opportunity to apply for the approval of qualifications despite different forms of learning). It is coherent with the approach based on competence, and not on the way of its acquisition (thanks to the requirements defined in relation to the knowledge, skills and other competences necessary to obtain qualifications at every level). Besides, it is coherent with the domestic system of professional qualifications (it synchronises particular levels of qualifications with the levels of qualifications determined in the law on the qualifications of jobs and specialisations for the purpose of the Polish labour market and the scope of its application).

It may be stated against this background that the implementation of the LLL programmes should be coherently and logically considered in them. It may be observed that every level of professional certification reflects another level of professional competence in accounting. It cannot be said that every level requires also a different level of awareness in the area of professional ethics. It may be emphasized however that every level of certification - in view of increasingly high level of substantive knowledge of accounting - requires a different method of education of professional ethics.

\section{The spectrum of people affected by the education of professional ethics in accounting within the LLL programmes}

The LLL programmes dealing with teaching professional ethics in accounting should include a decisively larger group of people than just accountants. All the people whose work contributes to a high quality of accounting information systems should be made sensitive to the accounting professional ethics.

In Poland, the Code of Professional Ethics in Accounting initiated by the author of the present article and published by the Accountants Association in Poland (SKwP) in 2006 does not mention the term accountant even once [www3]. (Since 2013 the Code has been available in SKwP in five languages in a traditional book form. This deliberate idea, initially arousing controversy, was based on the commitment of all the people professionally connected with the accounting information system to obey the code principles as a point of honour. And the Code uses the phrase a person dealing with accounting defined there as a physical person performing accounting activities, management supporting activities, tax settlements and other public legal settlements in an entity as well as any other people connected with accounting through science, teaching or other forms of professional activity.

The set of principles presented in the Code of Professional Ethics in Accounting regarded as a moral framework of the profession of accountancy is binding for the people pursuing activities:

- within the accepted principles (policy) of accounting (the so-called accounting activities), in particular:

1) keeping books of accounts based on accounting documents recording business events in a chronological and systematic order,

2) comparison of the real state of assets and liabilities with the accounting data,

3) balance valuation of assets and liabilities and calculation of the financial result,

4) financial reporting and submitting other financial information,

5) gathering and storing accounting documents and remaining documentation required from the entity by the current balance law, 
6) conducting financial analysis resulting from the information function of the accounting system of the entity,

7) cooperation with the chartered accountant auditing the financial reports of the entity.

(These activities also include the administration of the accounting information systems, offering explanations about the application of accounting principles in practice and promotion of the knowledge of principles of doing accounts.)

- within the adopted system of management of the information created in the accounting system of the entity as well as from other sources, including in particular:

1) submitting data to create the entity strategy,

2) making operational plans and giving advice on their implementation,

3) controlling business operations and related costs,

4) multi-aspect valuation of the entity performance,

5) offering business advice and consulting in the entity,

6) designing, implementing and servicing the accounting information systems in the entity,

7) activities and analyses aimed at the synchronization of operational activity with the entity strategy, to support business decisions made by the entity managerial staff,

8) work connected with the internal reporting system and other activities in the area of management accounting.

(These activities also include the promotion of concepts of management supporting accounting solutions.)

- consisting in the documentation of tax duties and other public legal duties by fulfilled by the entity, including in particular:

1) gathering information and keeping records indispensable to make tax settlements and other settlements on account of public legal grounds,

2) completing documents connected with taxes and other public legal titles,

3) explanation of tax problems and other public legal benefits.

(These activities also include the promotion of knowledge of public legal settlements).

The spectrum of people affected by the duty of ethical conduct in accounting, resulting from the original and active way in which it is defined, is not indifferent to the way of being educated in the area of professional ethics in accounting. It allows them to perceive a wide range of professional competences in which professional ethics in accounting should be reflected.

The aforementioned review of activities defining a person dealing with accounting, a potential participant of the LLL programme, is to support the conclusion that: the application of appropriate methods of teaching of the principles of professional ethics to such diversified groups of stakeholders of the LLL programmes is an issue of utmost importance if the teaching process in this area is to be effective.

\section{Case studies and ethical dilemmas in the LLL programmes}

The educational methodology is abundant in variety of forms and methods of teaching. Case study is a method of a high teaching efficiency in the area of developing skills and reinforcement of knowledge. The application of this method requires, however, a prior cautious consideration of the level of knowledge and skills which are to be developed thanks to this method. It is especially essential in the LLL programmes in the area of accounting.

The popularity of case studies results from the fact that they allow for the development of concrete skills. They are simulations of phenomena and situations - acquired thanks to a 
selective and orderly choice and/or intended chaotic description of facts - allowing the learner to sense authentic determinants, unassistedly find the methods of analysis, make comments and give presentations. Thanks to such features case studies allow not only for the self-verification of the knowledge so far. They generally help realize its interdisciplinary character and let it develop.

The teaching effectiveness of this method results from the fact that due to the personal pursuit of the whole analytical procedure of the practical problem, discussing the results at a large forum of course participants, it creates an opportunity to remember well both the knowledge and the way of using it. (It is known that you remember 10\% of what you have read, $20 \%$ of what you have heard, $30 \%$ of what you have seen. $50 \%$ of what you have seen and heard and as much as $90 \%$ of what you have you have done yourself).

The application of case studies in the LLL programmes in accounting and professional ethics is especially well grounded. The features defining a person dealing with accounting are decisive; among them an important position is held by practical skills in different areas and the necessity for ethical accomplishment of tasks, very often much diversified. The development of these features is a serious challenge in the period of university education as well as after its completion, within the LLL programmes. In the case of the latter, the application of case studies is nothing but a necessity, the LLL programmes participants are experienced to a certain degree and a traditional transfer of knowledge may not be insufficient but definitely improper as the only teaching method.

On the basis of the author's own experience connected with teaching accounting, it should be stated that case studies seem to be (1) the best and (2) simultaneously the cheapest way of presenting examples of the real business world to the participants. The best because a good case study is usually prepared on the basis of observation of an existing company or another economic organisation and describes true to life, often complicated situations and decision problems. A case study usually includes descriptions and data in values and measures found in the business activity of companies, which enriches the knowledge of the participants of the scale of the phenomenon, activity or event as well as the determinants of its occurrence. A case study is at the same time the cheapest way of developing practical skills, as the cost of a case study (or acquiring the right to use it) is incomparably lower than a possible cost (and difficulties) connected with finding companies willing to grant traineeships to tens (or even hundreds) of participants. The problem becomes even clearer if one can notice that companies are rarely open to this kind of initiatives on the part of educators.

The presented features of case studies point to the advantage of this teaching method over those called traditional methods of passing knowledge; however, case studies are not deprived of drawbacks either.

From the point of view of a trainer, teaching accounting it may be said that case studies do not guarantee a 100 percent "development of the sense of responsibility" for the conclusions drawn from it. Even if the study is conducted of the basis of authentic data in the situations corresponding to authentic determinants, no participant feels a responsibility for the decisions made during the study because after all they are unreal. Thus, it is essential for the trainer applying this method to work out an adequate system of appraisal of work on the case study.

From the point of view of a participant in turn, the saturation of the teaching process with case studies may result in the "tiredness of this sort of analyses" and eventually in a counter desired teaching effect. Every case study requires from the participants a lot of attention, accurate identification of the problem and preparation for the discussion during the course. The choice 
of frequency of case study application is also an important issue in planning the process of implementation of the substantive programme.

The choice of an "optimum case study in terms of teaching" is the first step in the process of the teaching process support. The next step is to plan the scenario of discussion which should take effect in class during the analysis of the selected case. The prepared scenario of case study is usually in the form of the so-called teaching notes planning the course and direction of the case study in the strict sense.

On the basis of observations made by university teachers and trainers of the LLL programmes pursued in Poland, it may be stated that there are three parallel schools of application of teaching notes. The first school prefers using teaching notes already published - usually written by the authors of case studies - and exact following their teaching suggestions and solutions presented there. The second school generally needs already published teaching notes, but only in order to better understand the "intentions" of the case study authors and realise the suggested teaching approach. With this kind of approach, a glimpse at the author's teaching notes is only a basis on which their own scenario of discussion is built, and their own teaching notes. A university teacher or trainer in this school - as it may seem - is apparently more creative and involved in building a teaching process than a teacher and trainer in the first school, but they take risk (perhaps not really consciously) that their own teaching notes (in particular when the case study is used for the first time) may "insufficiently deeply penetrate the teaching possibilities" connected with this case study. The third school is created by "independent university teachers and trainers". Such teachers or trainers, as a matter of principle, do not need any case studies at all. They try to prepare their own scenario of discussion with the participants only on the basis of the case study text and the possessed knowledge and teaching experience gained so far. May one risk a statement that the teachers or trainers in this school are most ambitious? The answer cannot be explicit. It is difficult to speak about ambition with regard to a trainer who possesses a lot of teaching experience in the application of case study methodology and preparing another study he usually has a complete vision of the framework and the way of holding a discussion. In such a case, the experience may give a perfect support to their work and justifies ignoring the author's designed teaching notes. And on the other hand, when inexperienced trainers disregard teaching notes, it may prove they are didactically immature, not ambitious. Teaching notes are an essential element of training preparation for teaching through the case study method. If trainers focus exclusively on the case study text and do not make use of teaching notes prepared for it, they represent an attitude of nonchalance or even professional ignorance.

In practice, well prepared teaching notes should:

1. raise the probability of holding a successful discussion about the case study from the teaching perspective;

2. help to save time necessary to prepare for the application of a selected case study;

3. support a sense of self-assurance thanks to a sample "teaching guide";

4. help to improve the methodology of writing trainer's own case studies;

5. contain author's intellectual contribution and therefore writing them is a great effort and should be treated as essential part of achievement of their author;

6. help to choose an appropriate case study, which is possible thanks to the information about the case study included in the teaching notes text describing the area in which the problem has been located and the way the study if to be pursued;

7. making it possible to realise to which extent the case study issues comply with the implemented programme and earlier selections of case studies; 
8. allowing for the synchronisation of the subject matter with analytical techniques.

Good teaching notes expose the author's knowledge and teaching experience. If they are accessible to other trainers, the author's know-how is used by the community, in favour of many stakeholders- educators and creates a high value intellectual capital in this environment.

It should be observed however that even the best teaching notes do not constitute the only and sufficient instruction for the trainer. Although they play an important role in conducting a case study, their application additionally requires very careful planning and many didactic considerations.

In the area professional ethics, case studies should have a form of ethical dilemmas. Such dilemmas stimulate the identification of the broken principles of professional ethics, analysis of solutions and - importantly - stimulate emotionally all the people involved in analysing them. The Ethics Commission of the Board of Accountants Association in Poland says that "from the point of view of a person dealing accounting, the ethical dilemma is born due to the participation in (or even observation of) internal or external facts, tasks, activities or other circumstances whose consequences have hallmarks indicating a threat of breaking the principles of the Code of Professional Ethics in Accounting. The ethical dilemma requires adopting a stance on it, which is connected with the need for the search for the best solution. The ethical dilemma is most often a conflict of interest, duty and loyalty. It should be emphasized that an argument or difficult situation at work may involve a person dealing with accounting may not always mean an ethical dilemma, even if on that occasion there could be a discussion about the principles of professional ethics in accounting. Many problems, including professional arguments may be substantive or organisational in character. It may be connected with the search for optimal solutions and making decisions in view of alternative variants. The key issue is then to identify the problem adequately and assess whether or not it is an ethical dilemma." [www4].

Ethical dilemmas may vary in capacity and form. They may be found as descriptions, dialogues and genre scenes. They may also have a multimedia form. Anyway, they should present an authentic situation; the one in which a conduct compliant with the principles of professional ethics could be threatened.

Taking into account the aforementioned remark on the necessity for the adjustment of the method to the substantive level at which the LLL programmme is implemented, a well prepared case study is essential. The ethical dilemma presented in a substantive but simplified situation may be not too interesting for the participants, and on the contrary - too complex subject matter may become a barrier difficult to cope with for the participants of a lower level of educational of LLL programme.

The Accountants Association in Poland has a Bank of ethical dilemmas created by the Ethics Commission of the Board of this association, to be used by all trainers within the LLL programmes offered by this organisation. Gathering ethical dilemmas is very difficult in practice. Their specific character is the reason why few practitioners express their readiness to share the knowledge of the situations referred to as ethically doubtful; and even if they were willing to do it, their description may prove too difficult for them. Thus, for years the Ethics Commission has been launching a competition for the best ethical dilemma in accounting, acquiring in this way subsequent materials, which are included in the Bank of ethical dilemmas. 


\section{Training of trainers of LLL programmes}

Taking into account the authenticity, and consequently the efficiency of teaching of professional ethics in accounting, the training of trainers involved in the LLL programmes is nothing but a must in this "soft" area. As remarked before, accounting trainers seldom have philosophical and psychological preparation, and this is the competence that is required in the presentation of ethical issues. It also requires some courage to speak about ethics and the skill of talking about awkward issues, arriving at a conclusion and also facing the conclusions that the only correct solution to a given ethical dilemma should be resignation from work.

The training of trainers who wish to apply ethical dilemmas as a teaching method should be affected on two planes. A brief presentation follows.

\section{Algorithm of conduct in the case of occurrence of ethical dilemma}

A trainer should know a recommended model of conduct in the case of occurrence an ethical dilemma. Such a model was created by the Ethics Commission of the Accountants Association in Poland and is easily accessible to trainers as well as others [www.4].

This model serves an auxiliary role and is dedicated primarily to the people affected by a dilemma related to professional ethics in accounting. It presents an algorithm only visually, which in such circumstances may be, according to the Commission, helpful in the selection of a path of appropriate proceeding.

For a trainer it is important that "the solution of an ethical dilemma in accounting depends on concrete circumstances of its occurrence and the idea of it. It should be borne in mind that generally a single perfect solution to a concrete ethical dilemma does not exist. When solving an ethical dilemma one should consider every time facts, ethical issues, legal regulations basic principles related to the case, internal procedures set to solve the problem, alternative ways of acting or consequences resulting from every possible ways of acting." [www.4]

The trainer should also make the participants aware that [www.4] the complexity of some ethical dilemmas leads to the recommendation of documenting the idea of the dilemma itself, the process of analysis and decision making at the key moments as well as the factors which have a direct impact on the undertaken activities, and at every stage of solving an ethical dilemma an analysis of principles of professional ethics in accounting is of the utmost importance.

\subsection{Methodological workshop on the application ethical dilemmas}

A specific character of methodological dilemmas makes it well-grounded for every trainer to do some exercise thanks to which they could feel and understand what every participants feels when solving an ethical dilemma. Owing to this conducting the dilemma case study during classes may be more conscious and effective. On the initiative of the Ethics Commission of the Accountants Association in Poland, workshops specially dedicated to trainers were held recently, i.e. in September 2016. 38 trainers participated there. The workshops were rated very highly. They were regarded very useful, as they were the first forum in Poland to exchange teaching experience in the area of professional ethics in accounting.

The formula of unconventional workshops really worked. It included primarily solving ethical dilemmas by constituted teams of trainers, followed by the presentation of a line of thinking pursued by each team. In total, eight dilemmas were analysed, two in each team.

In order to illustrate the problem, two examples of ethical dilemmas are presented below. Due to a limited space of the article the teaching notes are not included. 
During the course of discussion about the team analysis of ethical dilemmas in accounting, trainers did not present only the line of thinking but also its result. They characterised the behaviour of team members and the way they argued their stances. They answered questions: What were you feeling when solving the case study? Were you scared of the presentation of the results of discussion? What was the course of discussion and how did he team head manage it? What were his major problems? Was indifference and boredom with team work noticeable? Were case studies interesting and inspiring? Was a coach needed - in each team a different member of the Ethics Commission? Were the discussion conditions appropriate, i.e. could the discussion be held in an unhindered way?

The presentations of trainers' teaching experience acquired when teaching professional ethics was an important part of the workshops (the trainers conducting regular accounting classes).

Trainers - thanks to this formula - learned the structure of both a coherent and original lecture on ethics, they were made sensitive to the necessity for self-appraisal with regard to appropriate feature, behaviour and attitude in the teaching process, they realised the necessity for a proper allocation of teaching forms and methods in relation to different levels of professional training and they learned its example, they discussed different problems connected with trainers' everyday practice, the significance of which must not be disregarded in terms of professional ethics, including for example multi-media reinforcement of the course of professional ethics classes.

\section{Ethical dilemma no. 1}

A new director appeared in the company. He introduced changes and restructuring dynamically and computerised practically everything, including accounting. The new director considered the purchase of a new finance and accounting system necessary, as the software created by the company he had worked before is a way better than that used in the company now because it has a comprehensive managerial reporting potential.

An employee of the F\&A Department noticed soon that the purchased software was far away from professional solutions. He was forced to make some managerial reports beyond the system, and it was what the system was bought for. Every now and then he fished out some systemic errors. The employee reported it to the new director, to no avail though, contributing only to an unpleasant dissatisfied grimace of his face. He decided to give up then. The employee soon personally experienced the new director's dissatisfaction. The director did not like the results reported by the employee although they were compiled professionally. The director demanded from him analyses, resignation from the holiday planned long before and full availability because he planned another restructuring.

The new director did not conceal that the restructuring could be only avoided if some better results (for example lower costs) were presented at the general meeting of the company. He claimed that the results and their presentation were up to the employee, who had a great impact on a lot of things.

Task:

1. Comment on the presented situation, indicating what the employee should do in this situation and why.

2. Point to the principle or principles of the Code of professional ethics in accounting which could help him find a good solution. 


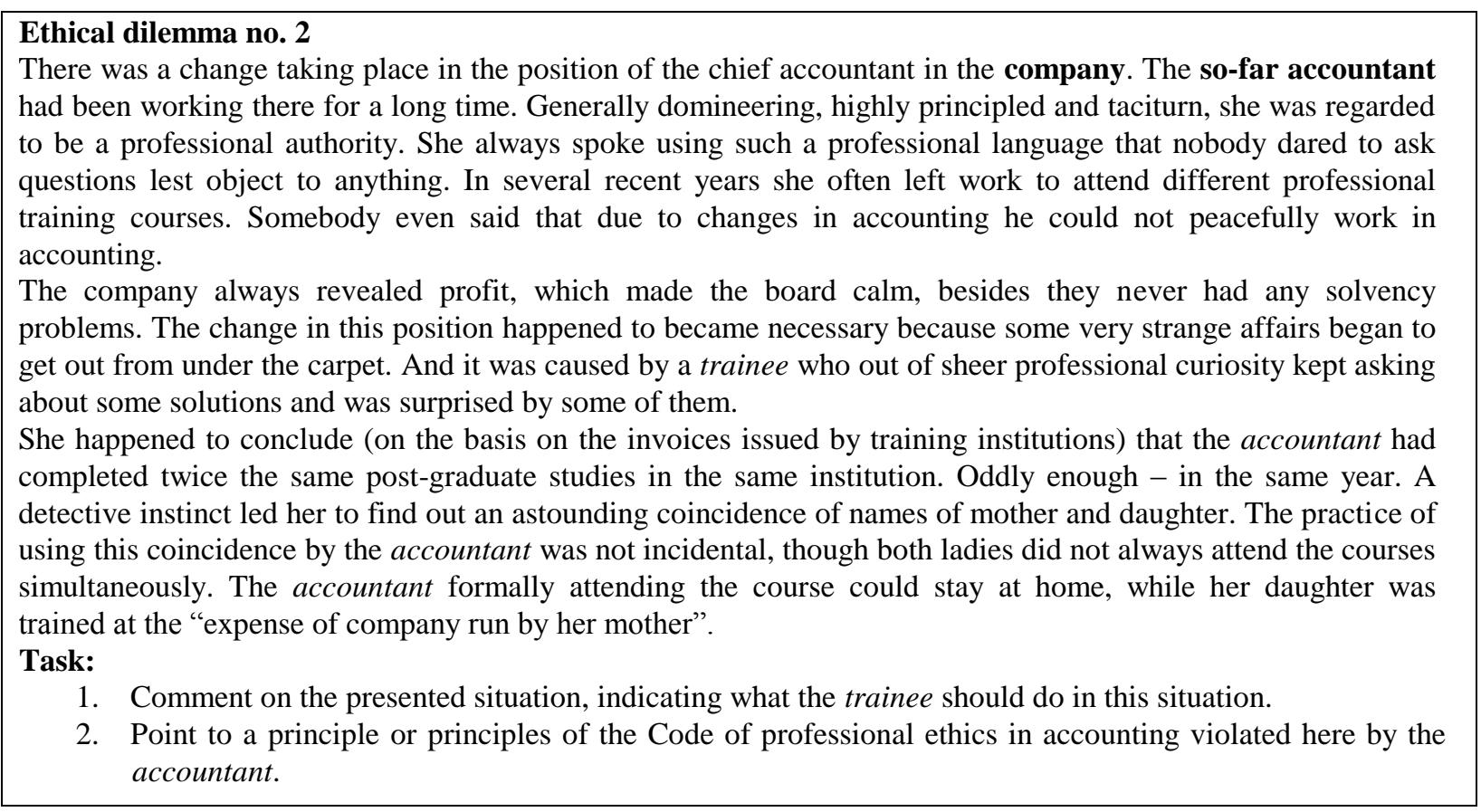

Source: author's own material presented during the workshops, for trainers of LLL programmes on ethical dilemma application, organised on the initiative of the Ethics Commission of the Main Board of the Accountants Association in Poland, September 2016.

As the educational effects in the area of professional ethics require, like the remaining knowledge and skills in accounting, verification adjusted to their character, during the workshops a methodological analysis was made of different forms of validation of educational effects and their usefulness in relation to the validation of educational effects of professional ethics issues in accounting.

Thanks to an in-depth analysis of pros and cons with regard to tests, dilemmas, essays and eventually oral examinations, the trainers together drew up a map of problems which every trainer of professional ethics in accounting should be sensitive to when selecting a form of examination. This part of the workshops also proved to be valuable.

\section{Conclusion}

Professional ethics in accounting is a great teaching challenge for trainers of programmes Lifewide Lifelong Learning. The difficulties are multi-layered, but primarily they result from the "softness" of the issue of ethics in accounting, cultural determinants in which teaching of this ethics is conducted or difficulties connected with the validation of educational effects. And eventually, from the necessity for a special preparation of trainers for the discussion of touchy problems which arouse emotions and wavering as well as for expressing certain attitudes with their behaviours which may be followed by the participants of classes, though frequently unconsciously.

In order to prepare trainers well, it may be useful to conduct special workshops for them on professional ethics in accounting.

The author's experience prompts that such workshops are desired by the LLL programmes trainers. They should have a carefully worked out formula and involve trainers actively. Through personally experienced difficulties in analysing ethical issues, even if they are unreal for the trainers because they are presented in the form of ethical dilemmas, the trainers acquire - important for teaching participants - an awareness of features and situations characteristic of 
the course of an ethical dilemma analysis, gain sensitivity particularly to those of them which although new or difficult for them, require their special attention. In this way they improve their teaching competences which decide whether the trainers' behaviours - during the classes devoted to professional ethics in accounting - will be assessed by their participants as either trustworthy and worth following or artificial and insincere.

\section{Literature}

Armstrong M. B., Ketz J. E., Owsen D. (2003). Ethics Education in Accounting: Moving toward Ethical Motivation and Ethical Behavior. Journal of Accounting, no. 21, pp. 1-16.

Code of Ethics for Professional Accountants (2016). The International Ethics Standards Board for Accountants (IESBA), The International Federation of Accountants (IFAC).

Code of professional ethics in accounting. Accountants Association in Poland, Warsaw 2007.

Grabowski R, Karmańska (2014). Challenges Faced by Polish Lifewide Lifelong Learning (LLL) Educators as Exemplified by Accounting, Proceedings of The 12th International Conference "Lifelong Learning: Continuous Education for Sustainable Development", SaintPetersburg, Russia, Volume 12, Part I, pp. 322-324.

Karmańska A., Grabowski R. (2014). Polish Lifewide Lifelong Learning (LLL) in the field of business as exemplified by Accounting. Proceedings of The 12th International Conference "Lifelong Learning: Continuous Education for Sustainable Development", Saint-Petersburg, Russia, Volume 12, Part II, pp. 269-273.

Koumbiadis N., Okpara J. O. (2008). Ethics and Accounting Profession: An Exploratory Study of Accounting Students in Post-Secondary Institutions. International Review of Business Research Papers, vol. 4, no. 5, October-November, pp. 147-156.

Maruszewska E. W. (2011). Ethical Education of Accounting Students in Poland. General and Professional Education, 1/2011, pp. 26-30.

McPhail K. (2013). Accounting Ethics. La Trobe University, SAGE Publications.

Mirskehary S., Yaftian A., Wickremasinghe G. (2009). Business Ethics and Accounting Students: Australia, South Asia and East Asia. Asian Journal of Finance \& Accounting, vol. 1, no. 2, pp. 146-162.

Said K., Al-Tarawneh K. I. (2013). Ethics and Postsecondary Accounting Curriculum in Bahrain: Perspective from Faculty Members. Journal of Accounting and Taxation, vol. 5 (3), September, pp. 65-82.

[www1] iaesb.org/ (available as of 10.09.2016)

[www2] skwp.pl/Certyfikaty,zawodowe,13177.html (available as of 10.09.2016)

[www3] skwp.pl (available as of 10.09.2016)

[www4] skwp.pl/Rekomendacja,11024.html (available as of 10.09.2016) 